\title{
Viva Pêcheux, Orlandi e Guimarães! Para ler o arquivo hoje: 20 anos... Labeurb ${ }^{1 *}$
}

No desafio de apresentar esta resenha, destaco, inicialmente, o gesto de interpretação que mobiliza o nome próprio, Labeurb - Laboratório de Estudos Urbanos, por uma enunciação cujo efeito mais imediato seria o de celebração dos "20 anos de História” desse núcleo que se formou, na Universidade Estadual de Campinas (Unicamp), com o papel de desenvolver pesquisa multidisciplinar, atividades de extensão e produção cultural. Ainda que sejamos, num primeiro momento, tomados pelo apelo de um ordenamento cronológico dos fatos no ressoar do enunciado é tempo de comemorar, resposta mais evidente à injunção à interpretação do decurso do tempo como um marco de significação das coisas dadas a saber, sugiro que relógios e calendários sejam apenas ferramentas iniciais de ancoragem à leitura.

Na decalagem espaço - tempo que (per[d)ura] 20 anos, a referenciação de algo com valor de memorável por uma relação espaço-temporal perene, demanda compreender que é o "tempo que lhe dá sentido", como sugere Guimarães (2013, p. 170)[1]deslocando, discursivamente, a aparência estática da localização do Labeurb na geografia da Unicamp: “... demora a leste do campus da Unicamp em Barão Geraldo (...) Esse arcaísmo, demora, aqui está para significar a relação do tempo com as coisas no espaço. O que está no espaço está ali historicamente, num certo tempo, numa certa conjuntura".

A criação de um espaço especializado no "saber urbano e linguagem", que deriva do Núcleo de Desenvolvimento da Criatividade (NUDECRI), pode ser compreendido como uma diferença que se marca na ordem do discurso científico extrapolando limites mais que geográficos (IEL, Unicamp, Campinas, Brasil) discursivos (transbordando as fronteiras do conhecimento científico e fundando um espaço de pesquisa acerca da cidade, da linguagem e da tecnologia). A percepção da temporalidade por uma diferença na ordem discursiva é, portanto, fundamental para entendermos, para além de aspectos meramente estruturais, o projeto edito-

1

* O Laboratório de Estudos Urbanos (Labeurb) foi criado, em 1992, dentro do projeto "O Sentido Público no Espaço Urbano" que resultou da proposta de revitalização do Núcleo de Desenvolvimento da Criatividade (NUDECRI) da Unidade Estadual de Campinas (Unicamp).

** Graduada em Comunicação Social / Jornalismo pela Universidade Federal de Minas Gerais - UFMG, mestre em Memória Social pela Universidade Federal do Estado do Rio de Janeiro - UNIRIO e doutoranda em Linguística pela Universidade Estadual de Campinas - UNICAMP. E-mail: angela.jornalista@gmail.com. Endereço postal: Rua Sérgio Buarque de Holanda, 571 - Campinas - São Paulo - Brasil. 
rial do livro Cidade, linguagem e tecnologia: 20 anos de História, organizado por Eduardo Guimarães. Ou seja, não se trata apenas de um e-bookque, dividido em quatro partes, reúne nove artigos científicos, um relato acerca da história do Labeurb, duas poesias e um registro fotográfico de publicações e de ações desenvolvidas junto a comunidades acadêmicas e não acadêmicas.

Uma leitura reversa, "folheando" (na verdade, descendo a barra de rolagem) o $e$ book de trás pra frente, pode ser produtiva aos sentidos. Ao final da obra, o "itinerário histórico-fotográfico" do laboratório traz imagens, por exemplo, de grafiteiros e de pesquisadores, indicando o trabalho de aproximação de dois saberes distintos (o saber urbano e o saber acadêmico / científico). O Labeurb traz à cena acadêmica outras formas de escrita pelas quais irrompe na cidade o saber urbano, fazendo circular sentidos que significam o espaço (urban[izad]o) e que significam os sujeitos (urban[izad]os). Ou seja, rompe os limites geográficos e discursivos (por uma proposta multidisciplinar, mas balizada pela incorporação da noção de discurso) para interrogar como se dá, no espaço da cidade, modos de produção simbólica que administram os sentidos do / sobre o urbano e para deflagrar diferentes lugares de pertencimento à cidade, bem como o jogo de forças que divide o social, nomeado como o político no interior das formulações da Análise de Discurso e da Semântica do Acontecimento.

O relato fotográfico retoma ações, como o projeto "Cidade Atravessada" que deu visibilidade a manifestações culturais presentes no espaço da cidade. Destaca ainda formas de expressão artística consideradas marginais no jogo de forças que divide o social, suscitando, a partir de outros modos de articulação de escrita da cidade e do espaço acadêmico formas de resistência face aos sentidos legitimados por interpretações hegemônicas presentes na memória social. E, não por acaso, a poesia do pesquisador Carlos Vogt compõe esse memorial apresentando, como lembrete, a relação tempo - contratempo.

Ao itinerário - histórico - proposto pelo conjunto de imagens, fotos, folders e recortes de publicações, que apontam outras materialidades produtivas aos estudos discursivos, antecede uma narrativa apresentada por Eduardo Guimarães. O organizador da obra é o responsável pelo relato no qual o narrador, convocando para si o papel de "historiador da ciência", se mostra interessado em "acontecimentos da ciência, das instituições" (2013, p. 169). Através de recortes de documentos relativos à pesquisa e à administração do Labeurb, bem como informações adicionais, são descritas as parcerias institucionais. Guimarães mostra ainda como o objeto de pesquisa ganha contornos de significação privilegiando o urbano como uma produção simbólica e constituindo um lugar de produção de conhecimento sobre o discurso. Ao mesmo tempo, constitui-se um lugar de formação e de atuação do pesquisador - e docente - 
que se dedica a investigar os modos de produção dos sentidos e dos sujeitos no espaço da cidade tendo como pressuposto a teoria discursiva. Fundada pelo filósofo francês Michel Pêcheux, a teoria, também conhecida como a vertente materialista da Análise de Discurso, foi desdobrada no Brasil a partir do trabalho de Eni Orlandi. É inquestionável que a fundação do Labeurb terá um papel importante na irrupção de um lugar de autoria na produção científica brasileira, que, na deriva de pressupostos formulados por Pêcheux, desenvolve um gesto teórico próprio de interpretação não só no terreno da Análise de Discurso materialista, mas também nos campos da Semântica do Acontecimento, em seu diálogo com a Teoria da Enunciação e com a Teoria da Argumentação, e da História das Ideias Linguísticas.

Caminhando, portanto, de trás pra frente na leitura do e-book é possível destacar elementos que, com efeito de fecho, funcionam como um ordenador de fatos históricos. Mas, de forma sutil, o narrador, organizador do texto na função de editor, dá pistas ao leitor que permitem traçar um eixo de filiação do trabalho desenvolvido pelo Labeurb aos estudos discursivos. Ainda que tenha sido estabelecida uma frente multidisciplinar de trabalho afetada por uma política institucional da Unicamp de fomento à formação de núcleos na aproximação de diferentes áreas de pesquisa, o que permitiu a implantação do laboratório, os trabalhos de Michel Pêcheux e de Eni Orlandi serão eixos norteadores de ações realizadas pelos pesquisadores do Labeurb. Essas informações permitem compreender as filiações teóricas e os percursos dos pesquisadores que, integrando a equipe do Labeurb, seja diretamente ou através de parcerias ou colaborações, participam da composição do e-book. Os artigos articulam, portanto, recortes que permitem perceber modos de produção simbólica da cidade e que recuperam percursos de análise - que compõem o arquivo do laboratório - relativos ao sujeito, às tecnologias da linguagem e à política.

Eni Orlandi, fundadora do Labeurb (onde ocupou a função de coordenadora por 19 anos), apresenta, em A palavra dança e o mundo roda: Polícia!, uma análise da linguagem videográfica e, recorrendo ao conceito de palavra-discurso, mostra como o processo de individuação do sujeito ocorre apoiado pela memória. A narratividade, que sustenta espaços de interpretação materializando / dando corpo ao espaço urbano, desencadeia os efeitos ideológicos da palavra-discurso, como acontece na música Kátia Flávia, a godiva do Irajá (1987), composta por Fausto Fawcett em parceria com Laufer, que inaugura algumas tendências que se desdobraram na música brasileira.

A voz é a materialidade destacada, a partir de recortes de um filme brasileiro, para a análise realizada por Pedro de Souza. Em $O$ nome da voz: processos de subjetivação no filme Tropa de Elite, o autor trabalha a questão da enunciação a partir do funcionamento da vozover que, exterior aos fatos narrados presentes na imagem, opera evocando, a partir da locução do narrador, uma memória. É nesse espaço que a discursividade se constitui pela constru- 
ção de um sujeito urbano por identificação imaginária a um herói que está pronto para a guerra.

Em Sujeito digital: sentidos de um novo paradigma, Cristiane Dias mostra, a partir recortes de materialidades que circulam com o discurso midiático, o deslocando do paradigma informacional e comunicacional, em que o controle comunicacional e informacional era a tônica, para o processo, mais recente, de significação da comunicação digital e no discurso sobre tecnologia digital, que produz um efeito de controle sobre a subjetividade.

Através de análise estrutural de construções onomásticas empregadas no espaço urbano, Bernard Bosredon descreve, no artigo Un cas d'onomastique pragmatique: les pratiques urbaines de la nomination, as diferenças de funcionamento e o alcance dos efeitos pragmáticos nos processos de identificação mobilizados, buscando verificar em que medida eles permitem ao falante identificar as regras de funcionamento ou se o uso dá de forma impensada.

Em Estacionar os sentidos em trânsito no espaço urbano, Marcos Barbai, face à presença excessiva de carros na cidade, analisa diferentes efeitos do estacionar a partir do discurso jurídico, da administração pública, do empreendedorismo e do humor, identificando as fissuras que deflagram as diferenças no pertencimento e no acesso à sociedade.

Claudia Pfeiffer traz recortes de arquivo constituído em trajetória de investigação acerca da constituição do sujeito escolarizado urbanizado, tendo em vista a injunção do dizer na urbanidade da língua. No artigo Percursos em um saber urbano e linguagem, a autora descreve, em especial, como recentes políticas públicas, que objetivam a educação para todos, funcionam na retomada de sentidos presentes desde a constituição do projeto republicado no qual estava estabelecida a igualdade de direito de acesso à educação, sendo a diferenciação produto de um esforço pessoal. Para a autora, a derivação se mostra em formulações equivalentes no interior de documentos ligados aos projetos de educação.

Para Mónica Zoppi-Fontana, que já vinha investigando o funcionamento do termo plágio, a surpresa face ao termo equívoco "autoplágio" foi o ponto de entrada na análise apresentada no artigo DEADLINE. A função-autor e os efeitos do discurso de produtividade na ciência. A autora traz recortes de textos de entidades que fomentam pesquisas e artigos científicos através dos quais estabelece um percurso de análise concluindo que a prática da autoria é afetada pelo critério de natureza quantitativa que pauta o discurso da produtividade científica. Isso leva a uma indistinção que se opera, atualmente, entre o "nome de autor" e "função de autor".

Os modos de significar o verbete música nas versões da Enciclopédia Britânica são analisados em Enciclopédia, estado e escola os sentidos de música por José Horta Nunes. O 
autor utiliza a Britannica Online Encyclopedia, em língua inglesa, e aBritannica Escola Onli$n e$, adaptada para o contexto escolar brasileiro, identificando uma divisão dos sentidos e dos sujeitos uma vez que, no primeiro caso, se observam sentidos presentes na história das ideias (arte / teoria) e, no segundo caso, algo que se produz como elaboração material (som/fazer).

Fechando a série de artigos, Suzy Lagazzi retoma, em Entre laços, alguns recortes de seu percurso como pesquisadora através do qual se dedicou ao estudo do funcionamento do político e do jurídico a partir de diferentes temáticas: o movimento social MST, que na busca pela terra se significa como não pertencendo ao espaço da cidade; o movimento MTST, que não se vê na luta pela terra por um sentido de estar fora da cidade, mas, de forma distinta, por uma luta de regularização fundiária; e os Juizados Informais de Conciliação, que dão visibilidade ao fato de que há pouca disposição à conciliação. Investigando ainda sentidos de cidadania, Lagazzi destaca que o "bem comum" funciona como a solução pacificadora da sociedade capitalista em seus pontos de contradição.

Na leitura do e-book que comemora o marco dos 20 anos do Labeurb, é produtivo compreender como objetos e lugares de pesquisa se constituem a partir da posição de autoria brasileira no desdobramento da teoria discursiva. Isso implica a constituição de gestos próprios de interpretação teórica para os quais foi fundamental a tradução de textos fundadores da teoria materialista do discurso, a consolidação dos campos da Análise de Discurso, da História das Ideias Linguísticas e da Semântica do Acontecimento no Brasil, a constituição modelos de pesquisa e de formação de pesquisadores que se replicam em outros centros de pesquisa brasileiros que constituem seus próprios laboratórios e o trabalho colaborativo entre instituições, que resulta em acordos de cooperação.

E, para finalizar este texto, confesso que, a princípio, senti certo estranhamento face à recente onda de homenagens a algumas de nossas referências que se destacaram, nas últimas décadas do século XX e início do século XXI, por derivas teóricas no campo discursivo da linguística. Entre elas, como já destacado neste texto, temos Michel Pêcheux, Eni Orlandi e Eduardo Guimarães[2]. Entretanto, como efeito de desfecho (à resenha e ao sentimento de estranhamento), destaco a consequente fundação do Labeurb acrescentando o argumento da comemoração como um ponto de (r)existência necessário à constituição dos sujeitos e dos sentidos na forma de uma desparecença ou de um desaparecimento de um outro lugar possível ao dizer ou daquilo que fala antes e em outro lugar[3]. Face à vontade de comemorar, a saber, os resultados do movimento de saber o saber e saber um outro saber, acredito que, o incômodo inicial torna-se produtivo à leitura do arquivo constituído em 20 anos de existência do Laboratório de Estudos Urbanos - Labeurb. Afinal, o "nossas" ("nossas referências") seria, portanto, a acusação indicial de filiação a uma escrita em sua relação a possíveis lugares de leitu- 
ra do que se estrutura, se reestrutura e se transforma tendo como efeito a contiguidade no espaço discursivo dos estudos da linguagem.

\title{
Bibliografia:
}

GUIMARÃES, Eduardo (org.). Cidade, linguagem e tecnologia: 20 anos de História. Campinas, SP: Labeurb, 2013, 212 p.

\begin{abstract}
Notas:
[1] GUIMARÃES, Eduardo. História de uma Área de Conhecimento: Saber Urbano e Linguagem. In: GUIMARÃES, Eduardo (org.). Cidade, linguagem e tecnologia: 20 anos de História. Campinas, SP: Labeurb, 2013, p. $169-184$.

[2] RODRIGUES, Eduardo Alves; SANTOS, Gabriel Leopoldino dos; CASTELLO BRANCO, Luiza Katia Andrade. (Orgs.). Análise de discurso no Brasil: pensando o impensado sempre. Campinas: Ed. RG, 2011. Esse livro resultou de homenagem feita à professora Eni Orlandi. A edição n ${ }^{\circ}$. 9, lançada em 2012, pela webrevista Discursividade prestou uma homenagem ao professor Eduardo Guimarães. Disponível em http://www.discursividade.cepad.net.br/EDICOES/09/09.htm.

[3] Lembro-me do dia em que a professora Eni Orlandi comentou, em sala de aula, acerca daquilo que reassoava na escrita contemporânea dos analistas de discurso pelo esquecimento da autoria inscrita a partir de seus trabalhos no campo da Análise de Discurso no Brasil. Creio que a questão extrapole o recurso do discurso relatado como garantia da propriedade na escrita acadêmica. A sobrevivência, pelo que (r)existe ao / no ato da palavra, implica em pontos de desaparecimento na deriva do dizer. A escuta das palavras de Orlandi, me gerou, inicialmente, o sentimento de culpa (como uma necessidade de revisão da minha escrita), acalmado pela compreensão de uma responsabilidade ética, afinal, sem esse outro - talvez, o outro ou o Outro - o sujeito seria somente grunhidos. Ética à qual a escrita acadêmica, inevitavelmente, não pode se esquivar.
\end{abstract}

